This is an electronic version of an article published in Stacie Traill (2014), Exploring the Terra Incognita of Access and Discovery: The Evolution of Cartographic Cataloging in the TwentyFirst Century, Journal of Map \& Geography Libraries: Advances in Geospatial Information, Collections \& Archives, 10:1, 48-61, DOI: 10.1080/15420353.2014.884035. Journal of Map \& Geography Libraries is available online at: http://dx.doi.org/10.1080/15420353.2014.884035

\title{
Exploring the Terra Incognita of Access and Discovery: The Evolution of Cartographic Cataloging in the Twenty-First Century
}

\section{Stacie Traill}

\begin{abstract}
Cataloging has seen substantial change since 2000, and the cataloging of maps, geospatial data, and other cartographic resources is no exception. The pace and scale of change, tied to the evolution of technology and cataloging/metadata standards, have been swift and broad. This paper highlights the most important changes and trends in the cataloging of cartographic resources during the first thirteen years of the twenty-first century through a review of the published literature, and summarizes the state of map cataloging today. The author concludes the paper by proposing future directions for research and practice.
\end{abstract}

\section{Keywords}

Cartographic Resources, Maps, Geospatial Data, Cataloging, Metadata

\section{Introduction}

Cataloging has seen substantial change since 2000, and the cataloging of maps, geospatial data, and other cartographic resources is no exception. The pace and scale of change, tied to the evolution of technology and cataloging/metadata standards, have been swift and broad. Some changes have been large, and years in the making, like the publication, testing, and implementation, of RDA: Resource Description and Access (American Library Association et al., 2010). Others have been smaller, but still impactful for map catalogers, such as the Library of Congress's 2008 decision to require geographic coordinates in full national-level records for cartographic resources (Library of Congress 2011b). Each of these changes has 
affected not only the day-to-day work of catalogers and others creating metadata for geographic information, but has also deeply impacted the ways in which libraries provide access and discovery services for cartographic resources. Through a review of the published literature, this paper seeks to summarize the state of map cataloging at the turn of the century, and highlight the most important changes and trends in the cataloging of cartographic materials during the first thirteen years of the twentyfirst century. The paper will conclude with a rumination on future directions for cartographic cataloging research, standards development, and practice.

\section{Map Cataloging at the Turn of the Century}

To understand how map cataloging thought and practice has evolved during the past dozen or so years, it is necessary to begin with an understanding of the state of map cataloging at the turn of the century. The indispensable summation of best practices and trends in map cataloging circa 2000 is found in the book Maps and Related Cartographic Materials: Cataloging, Classification, and Bibliographic Control (Andrew and Larsgaard, 1999). This comprehensive work contains papers addressing nearly every aspect of cartographic resources cataloging a librarian was likely to encounter during the late 1990s and early 2000s: descriptive cataloging of sheet maps, atlases, globes, maps on CD-ROM, and remotesensing images; cataloging of map series and map serials; cataloging of early printed maps and atlases; classification and subject cataloging of cartographic resources; retrospective conversion for map collections; and non-MARC metadata standards for geospatial data. Although technological advancement and the development of new cataloging and metadata standards mean that some of the details included in the articles are no longer applicable, many of the broad principles have not changed. The book has served catalogers since its publication as an essential practical reference tool. The seeds of the many changes to come during the next fourteen years are present in many of the discussions in Maps and Related Cartographic Materials, and many of the contributors have continued to share their expertise as technology and standards have evolved over the past decade or so. 
Another essential tool for catalogers of cartographic resources appeared early in the last decade: Cartographic Materials: A Manual of Interpretation for AACR2, 2002 revision, $2^{\text {nd }}$ ed. (AACCCM 2003). Published in 2003 in loose-leaf format to enable easy updating, Cartographic Materials is a critical reference tool for map cataloging under AACR2. Mangan (2007) discussed the development of the second edition of Cartographic Materials, describing extensive work done during the 1990s to revise and develop AACR2 Chapters 3 and 9, which deal with cartographic resources and electronic resources respectively (Mangan 2007, 38-40). The need for such a manual persists despite the publication and implementation of RDA: as Mangan put it, "One of the major changes in the principles from AACR2 to RDA is the acknowledgment that a cataloger will need to consult a more detailed, specialized interpretative manual in order to sufficiently describe a resource" (Mangan 2007, 43).

\section{FRBR, RDA, and Maps}

Any discussion of cataloging changes during the first part of the twenty-first century must begin with Functional Requirements for Bibliographic Records (FRBR) and RDA (IFLA 1998; American Library Association et al. 2010). FRBR was originally published in 1998, and its conceptual model underlies RDA. RDA's development began in 2005, with an initial draft published in 2008. The final version was published in 2010, and RDA was tested by the U.S. national libraries and selected partners during late 2010. After extensive review of the results of the test, the Library of Congress announced that it would fully implement RDA on March 31, 2013.

Because the text of RDA was available in various drafts during the course of its development, and because many communities of cataloging practice contributed both formally and informally to its development, catalogers had ample opportunity to familiarize themselves with the content of RDA during its development and before and during the testing phase. Community engagement was an important aspect of RDA's development process, and this engagement is reflected in the literature of map cataloging published during the past decade or so. Observing that the development of cataloging rules for specialized materials by nonspecialists has resulted in "less than adequate policies that do not recognize the 
fundamental differences of spatial materials," Mangan expressed the hope that "because cartographic material catalogers are now involved in the process of the development of this new cataloging code, hopefully cartographic resources will fare better than in the past” (Mangan 2007, 24; 43)

But before the development of RDA began, catalogers grappled with FRBR. Map catalogers began engaging with FRBR not long after its publication, investigating how cartographic resources fit into FRBR's entity-relationship model, with particular focus on FRBR's Group 1 entities: work, expression, manifestation, and item (often referred to in brief as "WEMI"). Most investigators have sought to answer the question of how the FRBR work entity applies to maps. McEathron (2002) made the first attempt to answer this question. McEathron used case studies of specific maps to show that the work concept has the potential to greatly improve catalog utility for accessing maps and atlases. McEathron also concluded that catalog discovery of modern cartographic works would likely benefit from inclusion of work-level metadata (McEathron 2002, 190).

Other researchers have arrived at different conclusions with regard to the utility of the "work" concept for map cataloging. Larsgaard (2007) saw the applicability of the other FRBR Group 1 entities item, manifestation, and expression - to cartographic resources, but stated that "work ... is just not a usable concept" for maps. She noted the infrequency with which uniform titles (which often align with the "work" level in FRBR's hierarchy) have been used in map cataloging as evidence that the concept is not especially useful for maps. (Larsgaard 2007, 112). Larsgaard cited two possible reasonswhy the "work" concept may be less relevant for maps. First, Larsgaard saw FRBR as a model developed to elucidate relationships in literary and fine-art works rather than in non-fiction works, noting that "the full model seems not to apply easily or intuitively even to all text works (e.g. a textbook in Physics) (Larsgaard 2007, 112). Second, she cited the graphical nature of maps as potentially demonstrating the need for a different underlying model from one (such as FRBR) that is effective for textual resources. (Larsgaard 2007, 114). 
Kalf (2008) attempted to develop a theoretical approach to map cataloging using FRBR. Using McEathron's (2002) examples as a starting point, Kalf developed hierarchical "trees" showing WEMI relationships for Carte des sols de la Belgique (Soil map of Belgium) and Carte topographique de Belgique (Topographic map of Belgium). The latter reveals some of the challenges and complexities catalogers are likely to encounter in attempting to apply the "work" concept to maps: as Kalf said, "To this work are related several different publications created by the various historical manifestations of the Institut géographique national, a body which has changed names four times since 1831 ! In certain cases, there is also an official Dutch version" (Kalf 2008, 284). Despite these challenges, Kalf concluded that although information display in existing library catalogs and discovery tools is imperfect, representing relationships among maps via FRBR trees is ultimately helpful to users, revealing "the context and the environment of the work." (Kalf 2008, 288).

More recently, Morse (2012) examined how and whether maps express the full range of relationships among entities represented in FRBR and RDA. Like Larsgaard (2007), Morse found that "the nontextual nature of sheet maps makes them difficult to fit into relationship taxonomies developed primarily for textual resources" (Morse 2012, 245). She observed that few of the types and subtypes of relationships in RDA apply to cartographic resources, and that because RDA relationships "most easily relate to textual materials ... it is sometimes difficult to tell if they are appropriate for cartographic resources" (Morse 2012, 239). Nevertheless, Morse concluded that cartographic resources are highly related, but that "the detailed nature of their relationships has yet to be completely explored" (Morse 2012, 245).

Larsgaard (2007) and Morse (2012) both made the point that FRBR entities and relationships, particularly the "work" concept, might not be wholly appropriate for cartographic resources, while McEathron (2002) and Kalf (2008) both found utility in the application of FRBR concepts to maps. Following FRBR, RDA places clear emphasis the need to differentiate between closely related works and expressions, no matter what kind of resource is being cataloged. For map catalogers, this may mean that 
uniform titles will assume a much greater importance (and see much more frequent use) than they have traditionally had. RDA requires catalogers to distinguish resources embodying different works or expressions but having the same authorized access point. In practice, map catalogers closely following RDA's instructions will likely find themselves much more frequently adding MARC 130 fields qualified by date, place of publication, or another characteristic in order to make clear the relationship between the resource in hand and other closely related resources.

Investigation of the theoretical principles underlying RDA is critically important, but practicing catalogers are naturally deeply interested in understanding exactly how adopting RDA will affect their daily work. The practical application of RDA to everyday cataloging is beginning to receive more attention as more libraries implement RDA in the wake of the Library of Congress's full adoption of RDA in early 2013. Although little has yet appeared in the published literature, experienced map catalogers have given a number of presentations and workshops on RDA and cartographic resources. Andrew and Moore's workshop at the 2013 American Library Association Annual Meeting focused primarily on how to craft descriptions of maps using RDA rules and concepts with ISBD and MARC21 encoding (Andrew and Moore 2013). Reassuringly for catalogers, Andrew and Moore noted that creating MARC records for maps using RDA rules results in records that are not very different than records created using AACR2 rules. They emphasized changes in terminology and conceptual differences from AACR2, outlined specific changes in descriptive practice (such as the elimination of most abbreviations), and detailed the ways in which physical descriptions are constructed differently in RDA. Andrew and Moore also addressed RDA's emphasis on relationships, offering a few examples of how to indicate relationships between creators/contributors and works/expressions/manifestations. They noted that practice for showing all kinds of relationships under RDA is evolving, and cautioned catalogers to remain aware of further developments in this area. Andrew and Moore are two of three co-authors of a forthcoming monograph tentatively titled $R D A$ and Cartographic Resources, expected to be published in 
2014, and it is likely that map catalogers will rely on their work for guidance as they learn to apply RDA (Andrew, Larsgaard, and Moore forthcoming).

While it remains to be seen how RDA's FRBR-derived WEMI model and emphasis on relationships will be fully applied to cartographic resources, there is a firm foundation for further exploration, and the author expects to see more evidence of the thoughtful, principled application of RDA's models to cartographic resources in the near future. In many ways, the depiction of relationships among various FRBR/RDA entities is inextricably tied to the development of a successor to the MARC format. The Library of Congress's Bibliographic Framework Initiative (BIBFRAME) is one important example (though far from the only one) of the move toward a future in which discovery and access are enabled not by MARC records, but by linked data expressed through XML (Library of Congress 2011a). The BIBFRAME initiative seeks to develop a model and technical standard for expressing relationships among four high-level entities, which are similar but not identical to FRBR entities. The initiative's stated goals are to "differentiate clearly between conceptual content and its physical/digital manifestations; unambiguously identify information entities (e.g. authorities); leverage and expose relationships between and among entitities." (Library of Congress 2011a). BIBFRAME departs from the MARC model of independently understandable catalog records that aggregate information about the work, its manifestation, and its carrier in favor of linking different pieces of relevant information for individual resources via controlled identifiers expressed in XML. While it is too early to say how these efforts will affect cataloging, it is clear that massive change is likely as BIBFRAME is refined and moves closer to full implementation. Map catalogers have done much work during the past decade that will prepare them for this change, as evidenced by their familiarity with multiple metadata standards and metadata crosswalking.

\section{Geographic Metadata: Working with Multiple Metadata Standards}

Catalogers who work with geospatial data have long known that some familiarity with the metadata standards typically used by the agencies that produce that data is essential. In the United States, 
the Federal Geographic Data Committee's (FGDC) Content Standard for Geospatial Metadata (CSDGM) long filled this role (FGDC 1998). The FGDC content standard is only one of several that have been commonly used, however. Larsgaard (2005) offered a succinct summary of the various metadata standards (apart from AACR2/MARC) in use for digital geospatial data, including Dublin Core, FGDC/CSDGM, and ISO 19115, an international standard for geographic metadata first published in 2003. Larsgaard stated that "metadata records tend to have considerably more, and considerably more detailed, computer technical information in them than do catalog records, in part because they may be constructed for specific, technically skilled audiences, and in part because a geographic digital dataset is by no means as easily browsed - in order to determine its suitability for use - as is a hard-copy map." (Larsgaard 2005, 231). She concluded by advising libraries planning to create geospatial metadata to follow ISO 19115 (Larsgaard 2005, 237). ISO 19115 is the topic of Ahonen-Rainio’s 2005 article. She explained the need to develop an international metadata standard specifically for geographic data (as opposed to adopting a more general standard like Dublin Core) by describing the specific properties of geographic data these users require in order to evaluate the suitability of a particular dataset to their needs.

Reese (2006) recognized that map catalogers need facility and expertise not only in creating metadata in multiple standards, but also in transforming metadata from one standard to another. He outlined the problems and opportunities in crosswalking MARC metadata to FGDC and vice versa, and offered tools and solutions for accomplishing this. Noting that a greater focus on creation of non-MARC metadata was already a reality at his institutions, Reese predicted that map catalogers working with geographic datasets would eventually transition from the creation of MARC records to the creation of FGDC metadata (Reese 2006, 88). Kollen, Dietz, Suh, and Lee (2013) showed that Reese's vision is playing out in several academic libraries that have created dedicated catalogs for geospatial data. In a survey of eleven libraries with such catalogs, they found that most use FGDC/CSDGM or ISO 19115 as the content standard for geospatial catalog metadata, though some use Dublin Core or homegrown metadata schemas (Kollen et al. 2013, 285). Venturing beyond metadata standards for geographic 
information, Beamer (2009) examined three metadata standards intended for general use:

MARC21/AACR2, Encoded Archival Description (EAD), and Dublin Core/Resource Description Framework (RDF), and concluded that all three could be effectively used for map cataloging (Beamer 2009, 34).

Surveying the whole of the recent literature on geographic metadata is beyond the scope of this paper, but this small group of complementary articles offers a broad overview of metadata standards in use for geographic data, and the ways in which catalogers who work primarily with MARC records can (and do) create and manipulate metadata. It is clear that this is an area of high interest and growth in libraries, and map catalogers have the tools and expertise to be leaders in this arena.

\section{MARC-based Cataloging of Online Cartographic Resources and Geospatial Datasets}

The information revolution that came with the creation of the Internet was in full swing in 2000, but as the technology of the web rapidly evolves, so too must the methods catalogers use to describe and provide access to online resources. A gradual shift to other metadata standards is evident in many libraries, but the need for MARC-based metadata for general library catalogs and discovery systems remains. Although crosswalking FGDC or ISO 19115 metadata to MARC as Reese (2006) suggests is a good option when such metadata is readily available, it is not always possible. Map catalogers continue to need to understand how best to represent online and digital geographic information in original MARC records. Larsgaard (2006) offered welcome guidance to catalogers working with these resources. Although the publication of this article predates the publication of RDA and is thus firmly anchored in AACR2, many of the basic principles apply under RDA as well, and much of the information provided on MARC coding is still relevant. Especially valuable is Larsgaard's discussion of how to record geospatial reference information and planar coordinate data, key attributes of digital geospatial data with which catalogers who work primarily with print materials may not be completely comfortable (Larsgaard 2006, 21-24). 
Larsgaard's focus on descriptive access complements the work of Lage (2007), who focused primarily on access points in the cataloging of digital geospatial data. Lage argued that existing Library of Congress Subject Headings (LCSH) were inadequate as access points for digital geographic information, and encouraged the revitalization of earlier efforts to explore the creation of a genre/form vocabulary for cartographic resources (Lage 2007, 45-46). Lage identified a number of libraries that had adopted local practices of either adding uncontrolled genre/form terms in MARC field 653, or using established LCSH terms for that purpose in MARC field 655. While she commended the improvements to access made possible by such additions, she pointed out that such practices "illustrate the critical need for national standardization of subject access to GIS data through the creation of authorized subject, form, and genre headings" (Lage 2007, 52).

\section{Library of Congress Genre/Form Thesaurus for Cartographic Resources}

Lage's call for a controlled genre/form vocabulary for geospatial data resources was timely. In 2008, following the successful implementation of a genre/form thesaurus for moving images, the Library of Congress announced that cartography was one of five areas for which the Policy and Standards division would develop a genre/form thesaurus. In September 2010, the Library of Congress (LC) implemented terms for cartographic resources within its full genre/form thesaurus, Library of Congress Genre/Form Terms for Library and Archival Materials (LCGFT). The cartography project differed somewhat from LC's other genre/form projects, in that genre/form subdivisions used with topical subject headings were simplified and reissued concurrently with the new genre/form headings, which represented the specific concepts and types of cartographic resources that had previously been reflected in genre/form subdivisions. This change demonstrates an increased emphasis on faceted, post-coordinated genre/form access via a combination of topical and genre/form headings in separate fields, and a shift away from precoordinated subject strings representing multiple concepts and entities. For example, a tourist map of Paris would have received the pre-coordinated geographic subject heading Paris (France) - Maps, Tourist under pre-LCGFT practice. Following LCGFT practice, the same map would receive two 
headings to represent the same bundle of concepts: the geographic heading Paris (France) - Maps, and the genre/form heading Tourist maps. This approach also means libraries that undertake to update their existing cartographic resources records must make changes to genre/form subdivisions in concert with adding new genre/form terms in 655 fields.

According to Young and Mandelstam (2013), a hallmark of the genre/form projects has been "collaboration with the constituencies for whom the vocabularies were developed" (Young and Mandelstam 2013, 8). They noted that in developing the cartography vocabulary, "PSD relied heavily on expert catalogers to provide guidance," working with catalogers in LC's Geography and Map Division to develop lists of terms and policies for assigning them (Young and Mandelstam 2013, 10). PSD has also used discussion papers as a vehicle to gather input from broader specialist communities on proposed changes to already-implemented vocabularies. A recent example in the area of cartographic resources is the 2012 discussion paper seeking comment on the treatment of globes in LCSH and LCGFT, which has resulted in the revision of the LCSH heading for "Earth" and the expansion of the LCGFT term "Globes" to include globes of any celestial body (Library of Congress 2012; Library of Congress 2013).

\section{Geographic Coordinates and Repurposing Catalog Data}

That cartographic resources must be searchable and discoverable by geographic area is selfevident to specialists and users who rely on those resources, but the importance of this method of access has not always been clear to non-specialists. Mangan described the historical circumstances that led to the general acceptance of author main entry for maps, noting that "While it is now generally accepted in the cartographic community that the majority of inquiries for spatial materials are, in fact, area-based, as are most modern cartographic products, cataloging records for cartographic resources continue to feature an author main entry" (Mangan 2007, 25). Though map catalogers have long understood the importance of providing geographic access via subject headings and statements of geographic coordinates in catalog records, coordinates were optional under AACR2, and it was not always easy to supply them: LC practice was to supply coordinates "when readily available." Although coordinates are also optional under RDA, 
since 2008, the Library of Congress has required geographic coordinates in national full-level MARC records, and coordinates are now a core element under RDA for LC and the Program for Cooperative Cataloging. The availability of free web-based tools to determine geographic coordinates makes this practice possible. Bidney (2010) noted that LC "has been working toward adding coordinate information to all their authority records since this change occurred, so any library who copies catalog records from the Library of Congress will have this fundamental information in their own catalog" (Bidney 2010, 141). As a result, coordinate data is much more frequently present in both bibliographic records for cartographic resources and authority records for geographic entities.

Bidney also noted the importance of supplying coordinates in both human-readable textual form in MARC field 255 and in machine-manipulable coded form in MARC field 034 (Bidney 2010, 145). While coordinates recorded in MARC 255 enable text-based retrieval in traditional library catalogs, coded coordinate data in MARC 034 can be used to build geographic facets to narrow result sets in nextgeneration catalog interfaces, and it can be repurposed outside the general library catalog altogether, in the form of dedicated geographic search interfaces. Bidney identifies a number of such projects, and others are described in the literature. Johnston and Jensen (2009) described a small-scale project at the University of Minnesota in which coordinate data from MARC records was leveraged with the Google Maps application programming interface (API) to create a geographical interface for searching the library's map collections. Oehrli, Pridal, Zollinger, and Siber (2011) enumerated the problems with conventional text-based retrieval for maps, and discussed their efforts toward the development of a scalable, next-generation retrieval tool with a geographical interface based in part on coordinate and other data in MARC records (Oehrli, et al. 2011). These are merely two representative projects out of many; a more exhaustive treatment is outside the scope of this article, but it is clear that geographic coordinates have become a crucial element in cartographic cataloging, and that they that have a major role to play in ongoing efforts to develop better, more intuitive geographic search interfaces.

\section{Access to Early and Rare Maps}


The past decade also saw innovative methods to improve access to early and rare maps. Kowal and Martyn (2009) described a British Library project in which maps contained in rare books were digitized and cataloged. After investigating other metadata options, the project team selected AACR2 and MARC used within the library's ILS digital asset management module to catalog the digitized maps, since the ILS provided linking ability between descriptions of the maps and descriptions of the books containing the maps. Although these are somewhat unusual choices for a local digitization project, they highlight the need for catalogers to remain open-minded when choosing metadata and access solutions for local projects: the best solution depends on the tools, systems, and staff expertise available to a particular library.

With libraries placing greater emphasis on cataloging unique and rare collections, the need for updated standards, guidance, and tools for cataloging early and rare cartographic resources is clear. Beamer (2009) observed that "map cataloging often requires some detective work ... with early maps there is [occasionally] very little information other than the map image itself" (Beamer 2009, 19). Kandoian (2008) addressed the challenge of identification commonly encountered in cataloging early printed maps. Although this is not a new problem, the number of published reference works helpful in making such identifications continues to grow. Kandoian's cartobibliography is an extensive list of such resources, with annotations and examples of identifications revealed by certain resources. In the realm of standards development, the 2007 publication of Descriptive Cataloging of Rare Materials (Books) (DCRM (B)) has been followed by work on complementary companion standards for special format rare materials. Efforts to develop Descriptive Cataloging of Rare Materials (Cartographic) (DCRM(C)) have been underway since 2008, with a full draft released for public hearing preceding the 2013 ALA Annual Conference held in Chicago (RBMS Bibliographic Standards Committee 2011). According to the editorial team, when DCRM(C) is published, it will "replace the rules for cataloging early cartographic resources currently found in Chapter 3 of AACR2 and Cartographic Materials: A Manual of Interpretation for $A A C R 2$, second edition. It is also anticipated that the PCC RDA BIBCO Standard 
Record (BSR) will be updated to incorporate guidance on using DCRM (C) to create bibliographic records for early and rare cartographic resources under RDA” (T. Fell, message to MAPS-L mailing list, May 28, 2013). The harmonization of multiple standards and guidelines promised by DCRM(C) will undoubtedly prove enormously helpful in catalogers' efforts to provide access to early and rare maps.

\section{Conclusion}

The pace of change in map cataloging since the turn of the century has been swift, and every indication points to constant, rapid change as the norm for the foreseeable future. During the past decade, map catalogers have delved into the application of FRBR's entity-relationship model to maps, participated in the development of RDA, and worked to develop practical guidelines for applying RDA in the current MARC environment. They have also gained increasing familiarity and expertise with nonMARC geographic metadata standards, participated in the development of dedicated geographic search catalogs and interfaces, and grappled with how best to catalog digital and online geospatial datasets. They advocated for improved access to cartographic resources based on genre/form and geographic area, helped develop and implement the LCGFT cartography vocabulary, and demonstrated the usefulness of requiring geographic coordinates in bibliographic and authority records. They embraced opportunities to improve access to collections of rare maps, and helped develop a new standard for cataloging early and rare cartographic resources.

Much has been accomplished, but much work remains. In the realm of RDA, specialist cataloging communities continue to make progress on settled practices. For cartographic resources, descriptive practice under RDA for printed maps and atlases is well in hand, but online and digital maps and datasets still need attention. Since RDA is highly focused on expressing relationships among various entities, all types of cartographic resources would benefit from more work toward a principled approach to expressing relationships among them. The development of BIBFRAME as an XML-based linked data model and probable successor to MARC means that the clear depiction of relationships takes on additional importance, since the implementation of any linked data model will depend on such clarity to smoothly 
transition legacy MARC data when the time comes. Studies on the efficacy of LCGFT terms for cartographic resources discovery would be a welcome addition to the literature, and would help inform ongoing development and application of the thesaurus. Map catalogers should also play a role in the continuing evolution and development of geographic search interfaces, recognizing that familiarity with multiple metadata standards and how to crosswalk data between them is no longer optional.

It is an exciting (and scary) time to be a cataloger of any variety, but the world of cartographic and geographic information offers especially rich opportunities for catalogers and metadata specialists. Constant change may be the "new normal," but as long as the focus remains on providing the best possible discovery and access to cartographic resources, catalogers will find good solutions to the myriad challenges they face in the current era.

\section{References}

Ahonen-Rainio, P. 2005. Metadata for Geographic Information. Journal of Map \& Geography Libraries 2: 37-66.

American Library Association, Canadian Library Association, and CILIP: Chartered Institute of Library and Information Professionals. 2010. RDA: Resource Description and Access. http://www.rdatoolkit.org. Accessed November 30, 2013.

Andrew, P. and M. Larsgaard. 1999. Maps and related cartographic materials: Cataloging, classification, and bibliographic control. Haworth Information Press, New York, NY.

Andrew, P. and S. Moore. 2013. Maps the RDA Way! Workshop presented at the American Library Association Annual Conference, June 27-July 2. Chicago, Illinois. http://magirt.ala.libguides.com/loader.php?type $=\mathrm{d} \& \mathrm{id}=802199$. Accessed December 1, 2013.

Andrew, P., M. Larsgaard, and S. Moore. Forthcoming. RDA and cartographic resources. Chicago: ALA Publications.

Anglo-American Cataloguing Committee for Cartographic Materials (AACCCM). 2003. Cartographic materials: A manual of interpretation for AACR2, 2002 revision. ed. E. Mangan. 2nd ed. Chicago: American Library Association.

Beamer, A. 2009. Map metadata: Essential elements for search and storage. Program: Electronic Library and Information Systems 43: 18-35.

Bidney, M. 2010. Can geographic coordinates in the catalog record be useful? Journal of Map \& Geography Libraries 6: 140-50. 
Federal Geographic Data Committee (FGDC). 1998. Content Standard for Digital Geospatial Metadata. Washington, D.C.: FGDC. http://www.fgdc.gov/standards/projects/FGDC-standardsprojects/metadata/base-metadata/v2 0698.pdf. Accessed December 1, 2013.

IFLA Study Group on the Functional Requirements for Bibliographic Records. 1998. Functional requirements for bibliographic records: Final report. Munich: K.G. Saur.

International Organization for Standardization. 2003. ISO 19115:2003: Geographic information: Metadata. Geneva: ISO.

Johnston, L, and K. Jensen. 2009. MapHappy: A user-centered interface to library map collections via a google maps "Mashup.” Journal of Map \& Geography Libraries 5: 114-30.

Kalf, R. 2008. FRBR: An opportunity for map collections and map users? Liber Quarterly: The Journal of European Research Libraries 18: 276.

Kandoian, N. 2008. Cartobibliography for catalogers: Reference materials to support the identification of early printed maps. Journal of Map \& Geography Libraries 3: 45-78.

Kollen, C., C. Dietz, J. Suh, and A. Lee. 2013. Geospatial data catalogs: Approaches by academic libraries. Journal of Map \& Geography Libraries 9: 275-95.

Kowal, K., and C. Martyn. 2009. Descriptive metadata for digitization of maps in books: A British Library project. Library Resources \& Technical Services 53: 108-20.

Lage, K. 2007. Cataloging digital geospatial data: Current standards and rogue cataloging practices, Journal of Map \& Geography Libraries 3: 39-55.

Larsgaard, M. 2005. Metaloging of digital geospatial data. Cartographic Journal 42: 231-37.

Larsgaard, M. 2006. Cataloguing electronic cartographic materials: Standard cataloguing. Cartographic Journal 43: 5-26.

Larsgaard, M. 2007. FRBR and cartographic materials: Mapping out FRBR. In Understanding FRBR: What it is and how it will affect our retrieval tools, ed. A. G. Taylor, 111-15. Westport, Connecticut: Libraries Unlimited.

Library of Congress. 2011a. Bibliographic Framework Initative. http://www.loc.gov/bibframe/. Accessed November 30, 2013.

Library of Congress. 2011b. MARC 21 format for bibliographic data: National level full and minimal requirements. http://www.loc.gov/marc/bibliographic/nlr/nlr.html. Accessed January 12, 2014.

Library of Congress. 2012. Proposed treatment of globes in the LCGFT environment: Discussion paper. http://www.loc.gov/catdir/cpso/genre_form_globes.pdf. Accessed January 10, 2014.

Library of Congress. 2013. Library of Congress to revise the treatment of globes in LCSH and LCGFT. http://www.loc.gov/catdir/cpso/genre form globes final.pdf. Accessed January 10, 2014.

Mangan, E. 2007. Cartographic materials: A century of cataloging at Library of Congress and beyond. Journal of Map \& Geography Libraries 3: 23-44.

McEathron, S. 2002. Cartographic materials as works. Cataloging \& Classification Quarterly 33: 181-91.

Morse, T. 2012. Mapping relationships: Examining bibliographic relationships in sheet maps from Tillett to RDA. Cataloging \& Classification Quarterly 50: 225-48. 
Oehrli, M., P. Pridal, S. Zollinger, and R. Siber. 2011. MapRank: Geographical search for cartographic materials in libraries. D-Lib Magazine 17 (9).

RBMS Bibliographic Standards Committee. 2011. DCRM(C): Descriptive cataloging of rare materials (cartographic). http://rbms.info/dcrm/dcrmc/index.html. Accessed January 10, 2014.

Reese, T. 2006. Bibliographic freedom and the future direction of map cataloging. Journal of Map \& Geography Libraries 2: 67-97.

Young, J. and Y. Mandelstam. 2013. It takes a village: Developing library of congress genre/ form terms. Cataloging \& Classification Quarterly 51: 6-24. 